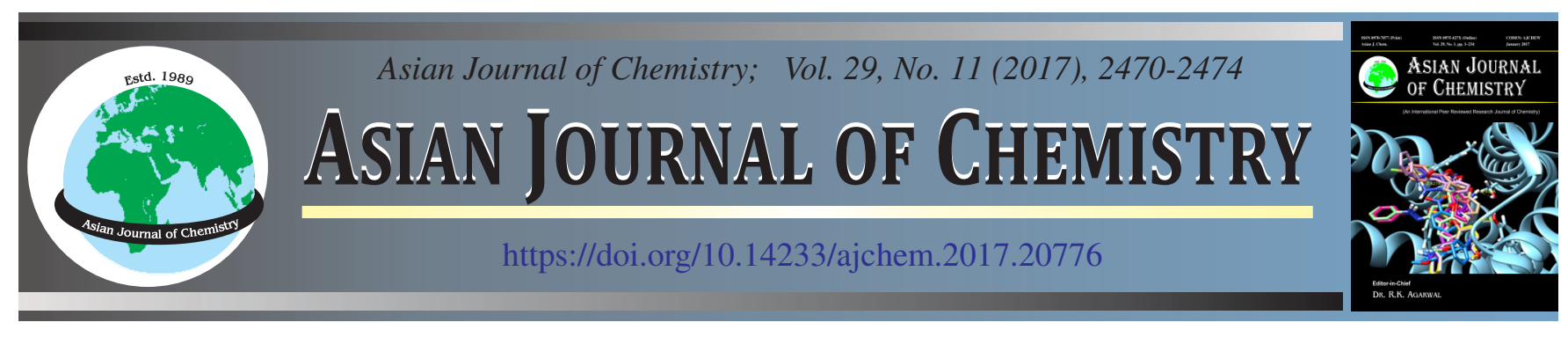

\title{
Extraction of Collagen from Cattle Skin and Synthesis of Collagen Based Flame Retardant Composition and Introduction into Cellulosic Textile Material by Graft Copolymerization
}

\author{
Nabiev Nabijon ${ }^{1}$, Md. Raju Ahmed ${ }^{1, *}$, Rafikov Adkham ${ }^{2}$ and Quan HenG ${ }^{1, *}$
}

${ }^{1}$ Department of Chemistry and Chemical Engineering, Wuhan Textile University, Wuhan, P.R. China

${ }^{2}$ Department of Technical Science, Tashkent Institute of Textile and Light Industry, Tashkent, Uzbekistan

*Corresponding author: E-mail: quanheng2002@163.com

\begin{abstract}
The composition for flame retardant treatment of cellulosic textile materials is proposed. The composition comprises an acrylic emulsion as a film former and a binder, collagen as a binder and flame retardant component, boric acid and potassium persulfate for chemically binding the components to a textile material. A technological scheme for applying the composition to the material has been developed. The processes that occur when the temperature was applied to the treated material were studied and graft copolymerization of acrylic monomers with collagen and cellulose was carried out. Based on the results of IR and PMR spectroscopic studies of collagen, cellulose, initiator, monomers and graft copolymer, a mechanism for interaction of the components was proposed. In the interaction of potassium persulfate with collagen and cellulose, radical active centers are formed, through which the grafted polymer chains are initiated and grown. Active polymerization centers are formed in the nitrogen atom of the peptide group of collagen and in the oxygen atom of the hydroxyl group of cellulose. The obtained material was tested for fire resistance: the material was not ignited when exposed to combustion for $10 \mathrm{~s}$; the mass loss was $4-8 \%$.
\end{abstract}

Keywords: Flame retardant, Cattle skin, Collagen, Cellulosic textile, Graft copolymerization.

\section{INTRODUCTION}

Textile materials, which are based on natural or chemical organic polymer fibers, flammable, flames spread quickly and can really be and are sources of ignition [1]. Fundamental improvement of the fire-retardant properties of textile materials can be in two main ways: the creation of non-flammable or heat-resistant fibers and the use of special flame retardant formulations that reduce their risk of fire. Conventionally used phosphorus, nitrogen, halogen, boron containing inorganic flame retardants, do not bind with the fibers of material, in the best case their physical adsorption takes place in the pores of the material. Over the time, desorption elution, spraying, etc., of flame retardant composition resulting in reduced fireresistant properties. According to the results of several authors [2-4] and present studies on flame retardant composition must contain at least two substances: fire retardant and polymeric binder [5]. If the polymer contains non-combustible elements such as nitrogen, halogen, silicon, boron and others then it will provide better result. The greatest beneficial effect is achieved by chemical fixation of flame retardant material with textile.
Collagen is one of the most common natural proteins. A review devoted to the production of collagen from the skin of animals and its physico-chemical properties, was made. The method for degreasing and drying animal skins and the intensification of the process of obtaining collagen by mechano-chemical treatment was proposed in several research works [6-8]. Isolation and study of the properties of collagen shows high reactive ability in oxidation reactions, hydrolysis, curing, tanning and other processes [9-13]. When exposed to temperatures in the drying and thermo-fixing processes resulting from the interaction of macromolecules of cellulose and collagen with potassium persulfate are formed the active centers i.e. radicals. Free radicals initiate vaccination collagen and polymethyl acrylate to cellulose. Grafting of acrylic and vinyl monomers to natural polymers - an important tool for modifying their properties [14-18]. The initiators of the grafting copolymerization may be potassium or ammonium persulfate [19-23].

The purpose of this research is to provide a flame retardant composition, strongly associated with the textile material and reduce the loss of material mass after exposure to flame. These objectives are achieved by developing the composition for 
flame-retardant treatment of textile materials consists of acrylic emulsion, collagen solution, boric acid, potassium persulfate and the impregnation of material in water-dispersed composition, drying and heat-setting the treated material. Boric acid and collagen solution serve as a flame-resistant component, acrylic emulsion - a water-insoluble film-forming and binder. Polycarbonate is responsible to form active centers of graft copolymerization. The formation of new bonds is usually established using spectroscopic methods. To prove the formation of radicals in the interaction of potassium persulfate with collagen and cellulose and to establish chemical bonds between cellulose, collagen, acrylic polymer was identified by IR and PMR spectroscopy. Research of the graft copolymerization of acrylic monomers with collagen and cellulose with the participation of potassium persulfate were carried out.

\section{EXPERIMENTAL}

For the flame-retardant processing of textile material, a new composition, containing solution of collagen, acrylic emulsion, boric acid and potassium persulfate was developed. To isolate collagen, unused and uncondensed waste of raw cattle skin was cut into pieces in the size of 3-4 mm and immersed in sodium hydroxide solution concentration of 3-5\%. Swelling and dissolution of the skin occurs over time. To accelerate the process, it was stirred until a homogeneous mass and warmed at $60^{\circ} \mathrm{C}$. After complete dissolution of the skin pieces, the solution was filtered by passing through a sieve. The filtrate was neutralized with acetic acid to neutral medium. In order to remove electrolytes from the solution the filtrate was dialyzed.

Acrylic emulsion was obtained by emulsion polymerization of methyl acrylate which is a milky white liquid, miscible with water in all proportions. Acrylic emulsion - not stratify for a long time, the relative viscosity of at least 1.75 , the mass fraction of residual monomer was not more than $0.35 \%$ and $\mathrm{pH}=6.0-8.5$. Boric acid weak inorganic tribasic acid; colourless crystals in the form of flakes, density $(\rho)=1.48 \mathrm{~g} / \mathrm{cm}^{3}$, moderately soluble in cold water, better - in hot was used. Potassium persulfate serves as polymerization initiator which is a white coloured fine crystal and highly soluble in water.

Production of fire-resistant materials produced on finishing production units. Process flow diagram of the flame-retardant treatment of textile materials:

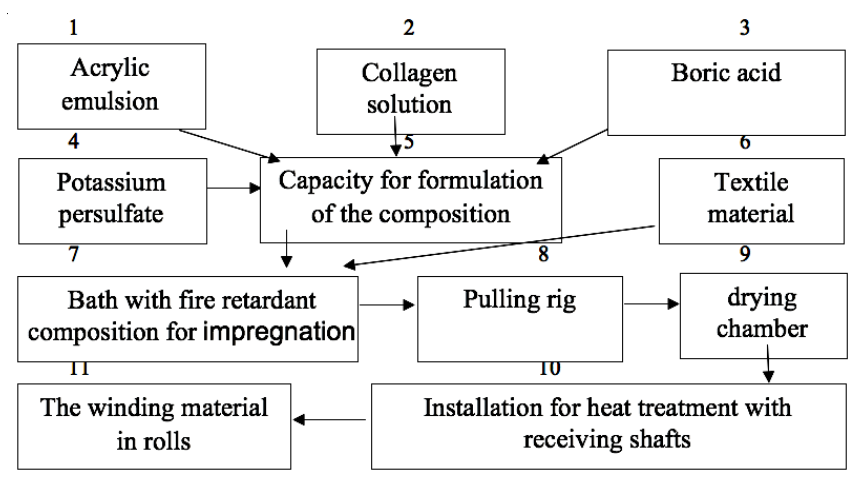

Estimated amount of acrylic emulsion (1 L), collagen solution (2 L), boric acid ( $3 \mathrm{~g})$ and potassium persulfate $(4 \mathrm{~g})$ was charged into a container for solution (5). Calculated amount of water was poured (1). The contents of tank thoroughly mixed until a homogeneous mass without inclusions, lumps and non-dispersed particles. The composition was introduced into the impregnating bath (7) where the textile material was fed under the force of pulling installation (8). The impregnated textile material was passed through squeeze rollers, dried in drying chamber (9) and then subjected to heat treatment (10). The fastening of the materials of fire-retardant composition was promoted by the pressure of pressing rollers. Ready made fire-proof textile material was wound in rolls (11).

Processes occurring in the material during drying, heat treatment and the systems of graft copolymerization were investigated. Graft copolymerization of acrylic acid (AA) and methyl methacrylate (MMA) to cellulose was carried out in presence of potassium persulfate. Synthesis of graft copolymers was carried out in a three-necked flask equipped with a stirrer, a thermometer and a reflux condenser under nitrogen. Monomer (acrylic acid, methyl methacrylate), cotton pulp fibers, solvent (water, dioxane) and the initiator were charged to the flask. The flask was immersed in a thermostat at a certain temperature. The synthesis of copolymers was carried out with constant stirring of reaction mass in the heterogeneous mixture. After reaching a certain time, the reaction mixture was removed from the thermostat; the copolymer was filtered off and washed several times with a solvent. The unreacted monomers and homopolymers were extracted with acetone. The resulting copolymer was placed in a desiccator connected to a vacuum pump and dried to constant weight.

IR spectra of the starting materials and copolymers were recorded on a Parker-Elmer System 2000 FT-IR spectrometer in the wavelength range of $400-4000 \mathrm{~cm}^{-1}$. The assignment of characteristic absorption bands was carried out according to the literature data. The PMR-spectra were recorded on a UNITY-400 + "Varian" nuclear magnetic resonance spectrometer at a working frequency of $400 \mathrm{MHz}$ in a solvent $\mathrm{D}_{2} \mathrm{O}$. At last, the flame retardancy of treated textile material was examined.

\section{RESULTS AND DISCUSSION}

The mechanism of initiation of graft copolymerization was analyzed by IR and PMR-spectra of collagen, cellulose, potassium persulfate and their reaction products. The IR spectra of collagen exhibited an absorption band at 1549 and 1656 $\mathrm{cm}^{-1}$, attributed to deformation vibrations of collagen $\delta(\mathrm{N}-\mathrm{H})$ bonds to secondary amine groups at $1549 \mathrm{~cm}^{-1}$, and for primary amines at $1656 \mathrm{~cm}^{-1}$. Absorption bands at 2929, 3070 and 3356 $\mathrm{cm}^{-1}$ assigned to the stretching vibrations of the same bonds and vibrations $\mathrm{vOH}, \mathrm{vCH}_{2}$. The absorption band of the deformation vibrations $\mathrm{vCH}_{2}$ identified at 1403 and $1452 \mathrm{~cm}^{-1}$ and the stretching vibrations $\mathrm{vC}-\mathrm{N}$ at 1241 and $1082 \mathrm{~cm}^{-1}$. The absorption band $652 \mathrm{~cm}^{-1}$ probably refers to vibration of NCO skeleton.

In IR spectra of cellulose, the absorption bands were observed at $616 \mathrm{~cm}^{-1} \delta \mathrm{C}-\mathrm{O}-\mathrm{C}$; at $1431-1430 \mathrm{~cm}^{-1} \delta \mathrm{CH}_{2}, \delta \mathrm{CH}$; at $1372-1317 \mathrm{~cm}^{-1}$ and $1164-1163 \mathrm{~cm}^{-1} \delta \mathrm{OH}, \delta \mathrm{CH}$. The absorption band $1114 \mathrm{~cm}^{-1}$ refers to the asymmetric stretching vibrations of the pyran ring. The valence vibrations of COC bridge have an absorption band at $1059 \mathrm{~cm}^{-1}$ (asymmetric) and $897 \mathrm{~cm}^{-1}$ (symmetrical). The absorption bands in $700-560 \mathrm{~cm}^{-1}$ region 
TABLE-1

CHANGE OF POSITION AND INTENSITY OF THE BANDS ABSORPTION IR-SPECTRUM IN THE INTERACTION OF COLLAGEN WITH POTASSIUM PERSULFATE

\begin{tabular}{cccc}
\hline Absorption bands $\left(\mathrm{cm}^{-1}\right)$ & Type fluctuations & Atoms, communication & Observed changes \\
\hline 524 & & $\mathrm{NCO}$ & Appearance of a new absorption band \\
1241 & Valence & $\mathrm{C}-\mathrm{N}$ & Intensity reduction \\
1262 & Valence & $\mathrm{O}-\mathrm{O}$ & $\mathrm{CH}$ \\
1334 & Intensity reduction & Intensity reduction \\
1567 & Symmetrical deformation & $\mathrm{NH}$ & Reduction intensity, offset \\
1637 & Deformation & $\mathrm{NH}$ & Bias \\
2997 & Deformation & $\mathrm{NH}$ & Bias \\
\hline
\end{tabular}

are likely related to the skeletal vibrations of the $\mathrm{C}-\mathrm{C}$ bonds or to the absorption of pyran ring. The broad absorption band at $3450-3300 \mathrm{~cm}^{-1}$ refers to $\mathrm{v}(\mathrm{OH})$. All the spectra contain a large number of sharp bands, which are due to the presence of large areas of high-molecular order. In the spectra of potassium persulfate strong absorption band at $1059 \mathrm{~cm}^{-1}$ refers to the symmetric stretching vibrations of $\mathrm{S}=\mathrm{O}$. Group bands in the region $2570-2136 \mathrm{~cm}^{-1}$ are likely related to the subtracting double bonds $\mathrm{O}=\mathrm{S}=\mathrm{O}$, and in the region of $690-558 \mathrm{~cm}^{-1}$ refers to $\mathrm{SO}_{4}{ }^{2-}$. Doublet at $1290-1262 \mathrm{~cm}^{-1}$, most likely appears as a result of oscillations -O-O- bonds of persulfate.

In the interaction product of collagen with potassium persulfate, the appearance of a new signal was observed which is referred to the band of peptide group. Table- 1 represents the change of position and intensity of the bands absorption IR-spectrum in the interaction of collagen with potassium persulfate.

As expected, significantly reduction of the intensity of $\mathrm{O}-\mathrm{O}$ bonds of PC can be seen. At the same time, decreases the intensity of the absorption band of $\mathrm{C}-\mathrm{N}$ and $\mathrm{C}-\mathrm{H}$ bonds of collagen, the absorption band $\mathrm{N}-\mathrm{H}$ of the peptide group is shifted. The observed changes indicate participation proton of peptide group or a $\mathrm{CH}$ group in the formation of active centers of the graft copolymerization. Moreover, the greatest changes in the form of a decrease intensity and bias refer to the bonds between nitrogen and hydrogen atoms of the peptide group, and not the primary amino group.

During interaction of cellulose with potassium persulfate, changes associated with cellulose hydroxyl groups, suggesting that participation in acts of initiation of these groups. Table-2 represents changes of the position and intensity of the bands absorption of IR spectra at interaction cellulose with potassium persulfate.

TABLE-2

CHANGES OF THE POSITION AND INTENSITY OF THE BANDS ABSORPTION OF IR-SPECTRUMS AT INTERACTION CELLULOSE WITH THE POTASSIUM PERSULFATE

\begin{tabular}{cccc}
\hline $\begin{array}{c}\text { Absorption } \\
\text { band }\left(\mathrm{cm}^{-1}\right)\end{array}$ & $\begin{array}{c}\text { Type } \\
\text { fluctuations }\end{array}$ & $\begin{array}{c}\text { Atoms, } \\
\text { communication }\end{array}$ & Observed changes \\
\hline 1262 & Valence & O-O & Intensity reduction \\
1337 & Expansion & $\mathrm{OH}$ & Intensity reduction \\
2850 & Valence & $\mathrm{OH}$ & Bias \\
2928 & Valence & $\mathrm{OH}$ & Bias \\
\hline
\end{tabular}

According to literature and spectroscopic studies, the reaction of the formation of active centers during the interaction of macromolecules of natural polymers with radical initiators can be represented by the following:

$$
\begin{gathered}
\mathrm{S}_{2} \mathrm{O}_{8}{ }^{2-} \longrightarrow 2 \mathrm{SO}_{4}{ }^{--} \\
\mathrm{SO}_{4}{ }^{--}+\mathrm{H}_{2} \mathrm{O} \longrightarrow \mathrm{HSO}_{4}^{-}+\mathrm{OH}^{\bullet} \\
{\left[\mathrm{C}_{6} \mathrm{H}_{7} \mathrm{O}_{2}(\mathrm{OH})_{3}\right]_{\mathrm{n}}+\mathrm{SO}_{4}{ }^{-}-/ \mathrm{OH}^{\bullet} \longrightarrow} \\
{\left[\mathrm{C}_{6} \mathrm{H}_{7} \mathrm{O}_{2}(\mathrm{OH})_{2} \mathrm{O}^{\bullet}\right]_{\mathrm{n}}+\mathrm{HSO}_{4}{ }^{-} / \mathrm{H}_{2} \mathrm{O}} \\
\mathrm{R}_{1}-\mathrm{NH}-\mathrm{CO}-\mathrm{R}_{2}+\mathrm{SO}_{4}{ }^{-} / \mathrm{OH}^{\bullet} \longrightarrow \\
\mathrm{R}_{1}-\mathrm{N}^{\bullet}-\mathrm{CO}-\mathrm{R}_{2}+\mathrm{HSO}_{4}{ }^{-} / \mathrm{H}_{2} \mathrm{O} \\
\mathrm{R}_{1}\left(\mathrm{R}_{2}\right) \mathrm{CHNHCOR}{ }_{3}+\mathrm{SO}_{4}{ }^{-} / \mathrm{OH}^{\bullet} \longrightarrow \\
\mathrm{R}_{1}\left(\mathrm{R}_{2}\right) \mathrm{C}^{\bullet} \mathrm{NHCOR}_{3}+\mathrm{HSO}_{4}-/ \mathrm{H}_{2} \mathrm{O}
\end{gathered}
$$

Thus, according to the results of theoretical and experimental investigations, active graft copolymerization centers appear in the interaction of cellulose macromolecules and collagen with potassium persulfate. To clarify the nature of the active centers and determine the growth reactions and breakage of the grafted chains, was examined IR spectra of grafted copolymers and PMR-spectra of the initial polymer, monomers and graft copolymers.

In IR spectra of copolymers, new absorption bands appear at $1113,1273,1329,1362 \mathrm{~cm}^{-1}$ (collagen-AA) and 953, 1019, $1281,1337 \mathrm{~cm}^{-1}$ (collagen-MMA), which probably belong to the valence vibrations of the new $\mathrm{C}-\mathrm{N}$ bands (Fig. 1). IR spectral analysis of the copolymers also indicate the inoculation of functionally-active polymers to the nitrogen atoms of collagen. Probably, in reaction involved nitrogen atoms of the peptide group are of protein macromolecules.

Interesting results were also obtained by analyzing the spectra of cellulose copolymers. All the copolymers have
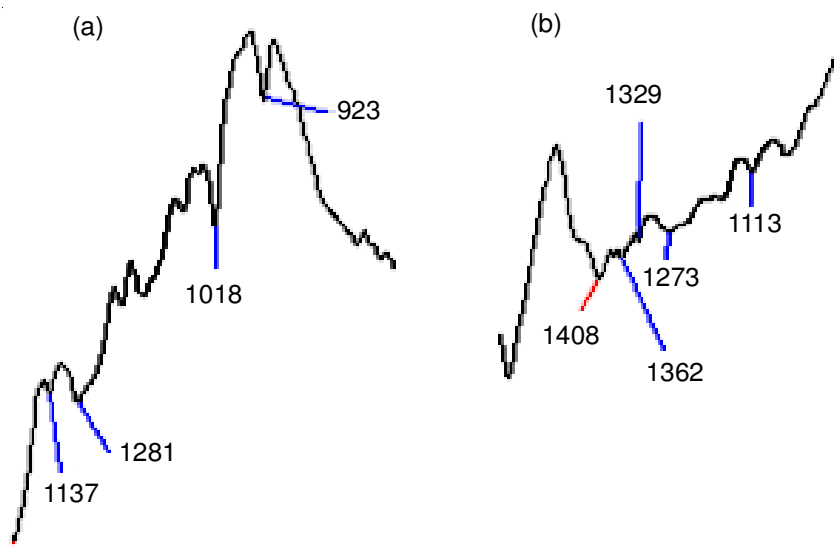

1200

800

$1 / \mathrm{sm}$

1400

1000

Fig. 1. Absorption bands of valence vibrations of $\mathrm{C}-\mathrm{N}$ bonds in IR-spectra of collagen with (a) methyl methacrylate and (b) acrylic acid 
crystalline nature, spectrum of which is manifested at 1374$1372 \mathrm{~cm}^{-1}$ and for the amorphous nature, the region at 2900$2898 \mathrm{~cm}^{-1}$. In copolymers which retain the bands of absorption valance and deformation vibrations of $\mathrm{CH}$ and $\mathrm{CH}_{2}$ groups, is almost undetectable absorption band of valance vibrations of the vinyl group monomers. Weak signals produce vibrations of carbonyl ester group of the monomers in the composition of the synthesized copolymers. In IR spectra of the copolymers, some new bands are found as compared with spectra of cellulose which appears absorption band at $1734-1720 \mathrm{~cm}^{-1}$, attributed to the stretching vibrations $\mathrm{C}=\mathrm{O}$ group of acrylic acid (AA) and methyl methacrylate (MMA). The position and intensity of absorption band of hydroxyl groups changes. In all copolymers, strong absorption bands are observed at 1030$1027 \mathrm{~cm}^{-1}, 1058-1055 \mathrm{~cm}^{-1}$, the band average intensity at $1116-$ $1113 \mathrm{~cm}^{-1}$ and at $1164 \mathrm{~cm}^{-1}$ are observed. These bands are related to the vibrations of simple ether bonds which are presented in Fig. 2. Reaction of initiation of the graft copolymerization of monomers to cellulose is most likely carried by the hydroxyl groups of celluloses.

In PMR-spectra, the cellulose that signals of proton chemical shifts $\mathrm{CH}, \mathrm{CH}_{2}$ groups. There are multiple signals relating to the protons of $\mathrm{OH}$ groups in the region of 2.5-4.5 ppm. PMR signal at 6.59 and $7.68 \mathrm{ppm}$ refers to protons $\mathrm{CH}_{2} \mathrm{OH}$. In PMR-spectra of the copolymers of cellulose with acrylic acid and methyl methacrylate found some changes compared with spectra of cellulose. The signals disappear at 6.59 and $7.68 \mathrm{ppm}$, the number of signals decrease and change their position at $0.5-2.0 \mathrm{ppm}$. There are intense and numerous signals in the region of 2.0-5.5 ppm. Analysis showing the disappearance of some signals in the copolymers $(2.71 \mathrm{ppm})$, an increase $(3.25 \mathrm{ppm})$ or decrease $(3.56 \mathrm{ppm})$ in intensity, offset (2.96 at $3.03 \mathrm{ppm}, 4.19$ at $4.29 \mathrm{ppm}$ and 4.43 at $4.59 \mathrm{ppm}$ ). Moreover, the displacement is observed mainly in the higher values of the chemical shifts. The mono signal at $5.19 \mathrm{ppm}$ turns into a triplet with peaks of 5.09, 5.20 ppm and 5.24 ppm. There are new PMR signals at 3.72, 4.12, 4.15 and 4.29 ppm (Table-3).
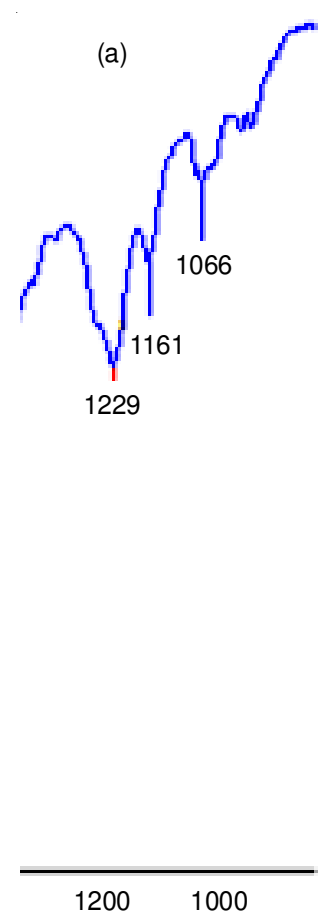

Fig. 2. Absorption bands of valence vibrations of C-O bonds in the IR-
spectra of collagen with AA (a) and MMA (b)

The displacement of signals indicates the involvement of protons in reactions of interaction between cellulose, the initiator and monomer. New signals are likely refer to protons of $\mathrm{OCH}$ and $\mathrm{OCH}_{2}$ groups, which linking graft polymers with cellulose. The observed changes in PMR spectra of copolymers confirm the results of the IR spectra analysis. Initiation of grafting copolymerization is carried through oxygen atoms of cellulose. Growth of grafted chains is occurred by radical mechanism.

Based on the results, reaction of initiation and growth of the grafted chains of the functionally active monomers to cellulose can be represented by the following reaction:

$$
\begin{aligned}
& {\left[\mathrm{C}_{6} \mathrm{H}_{7} \mathrm{O}_{2}(\mathrm{OH})_{2} \mathrm{O}^{\bullet}\right]_{\mathrm{n}}+} \mathrm{CH}_{2}=\mathrm{CH}(\mathrm{X}) \longrightarrow \\
& {\left[\mathrm{C}_{6} \mathrm{H}_{7} \mathrm{O}_{2}(\mathrm{OH})_{2} \mathrm{O}\right]_{\mathrm{n}}-\mathrm{CH}_{2}-\mathrm{C}^{\bullet} \mathrm{H}(\mathrm{X}) }
\end{aligned}
$$

TABLE-3

\begin{tabular}{|c|c|c|}
\hline \multirow{2}{*}{ Cellulose } & \multicolumn{2}{|c|}{ Copolymers } \\
\hline & Cellulose-acrylic acid & Cellulose-methyl methacrylate \\
\hline $0.37-0.48$ (weak doublet) & $0.37-0.49$ (weak) & $0.37-0.49$ (weak doublet) \\
\hline $0.80($ strong $)$ & $0.80(\mathrm{mid})$ & $0.80(\mathrm{mid})$ \\
\hline \multicolumn{3}{|l|}{1.24 (weak) } \\
\hline \multicolumn{3}{|l|}{1.75 (weak) } \\
\hline $2.00($ weak $)$ & 2.00 (mid) & 2.01 (mid) \\
\hline \multicolumn{3}{|l|}{2.71 (mid multiplet) } \\
\hline \multirow[t]{2}{*}{$2.96(\mathrm{mid})$} & $3.01(\mathrm{mid})$ & $3.03(\mathrm{mid})$ \\
\hline & 3.23-3.30 (mid double) & 3.25 (strong)-3.33 (mid doublet) \\
\hline 3.40-3.43 (weak doublet) & 3.41-3.44 (weak multiplet) & 3.42-3.43 (weak multiplet) \\
\hline 3.56 (strong) & $3.56(\mathrm{mid})$ & 3.57 (mid) \\
\hline 3.76 (weak) & 3.74 (mid) & 3.72 (mid) \\
\hline 3.85 (weak) & & 3.92 (weak) \\
\hline 3.98 (weak multiplet) & $3.96($ weak $)$ & \\
\hline 4.19 (weak wide) & 4.09-4.12-4.14-4.18 (mid multiplet) & 4.12-4.15-4.16-4.17 (strong multiplet) \\
\hline 5.19 (mid) & 5.11 (weak) & 5.09 (weak) \\
\hline 6.59 (weak) & 5.21 (weak) & 5.20 (weak) \\
\hline 7.68 (weak) & 5.26 (weak) & 5.24 (weak) \\
\hline
\end{tabular}

CHEMICAL SHIFTS (ppm, INTENSITY) OF PMR-CELLULOSE AND ITS COPOLYMERS 
TABLE-4

COMPOSITIONS USED FOR THE FLAME-RETARDANT PROCESSING OF TEXTILE MATERIAL

\begin{tabular}{cccccc}
\hline \multirow{2}{*}{$\begin{array}{c}\text { Variants of } \\
\text { compositions }\end{array}$} & \multicolumn{5}{c}{ Mass fraction of component (\%) } \\
\cline { 2 - 6 } & Acrylic emulsion & Collagen solution & Boric acid & Potassium persulfate & Water \\
\hline 1 & 8.0 & 10.0 & 2.5 & 0.020 & 79.480 \\
2 & 10.0 & 12.0 & 3.0 & 0.020 & 74.980 \\
3 & 12.0 & 14.0 & 5.0 & 0.025 & 68.975 \\
4 & 15.0 & 16.0 & 4.0 & 0.025 & 64.975 \\
5 & 18.0 & 18.0 & 6.0 & 0.030 & 58.970 \\
\hline
\end{tabular}

TABLE-5

FIRE RESISTANCE OF TREATED MATERIAL

\begin{tabular}{|c|c|c|c|c|c|c|}
\hline \multirow{2}{*}{$\begin{array}{l}\text { Sample size } \\
(\mathrm{mm} \times \mathrm{mm})\end{array}$} & \multicolumn{2}{|c|}{ Weight of the sample $(\mathrm{g})$} & \multirow{2}{*}{$\begin{array}{l}\text { Weight } \\
\text { loss }(\%)\end{array}$} & \multirow{2}{*}{$\begin{array}{l}\text { Time of exposure } \\
\text { to combustion (s) }\end{array}$} & \multirow{2}{*}{$\begin{array}{c}\text { Time } \\
\text { combustible (s) }\end{array}$} & \multirow{2}{*}{ Note } \\
\hline & Till test & After test & & & & \\
\hline $2.8 \times 10$ & 2.35 & 2.1 & 11 & 10 & 3 & Smolders \\
\hline $2.8 \times 10$ & 2.40 & 2.2 & 8 & 10 & - & Does not burn \\
\hline $2.8 \times 10$ & 2.60 & 2.5 & 4 & 10 & - & Does not burn \\
\hline $2.8 \times 10$ & 2.75 & 2.6 & 5 & 10 & - & Does not burn \\
\hline $2.8 \times 10$ & 2.90 & 2.7 & 7 & 10 & - & Does not burn \\
\hline
\end{tabular}

$\left[\mathrm{C}_{6} \mathrm{H}_{7} \mathrm{O}_{2}(\mathrm{OH})_{2} \mathrm{O}\right]_{\mathrm{n}}-\mathrm{CH}_{2}-\mathrm{C}^{\bullet} \mathrm{H}(\mathrm{X})+\mathrm{mCH}_{2}=\mathrm{CH}(\mathrm{X}) \longrightarrow$

$\left[\mathrm{C}_{6} \mathrm{H}_{7} \mathrm{O}_{2}(\mathrm{OH})_{2} \mathrm{O}\right]_{\mathrm{n}}-\left[\mathrm{CH}_{2}-\mathrm{CH}(\mathrm{X})\right]_{\mathrm{m}-1}-\mathrm{CH}_{2}-\mathrm{C}^{\circ} \mathrm{H}(\mathrm{X})$

The esterification of boric acid with cellulose at thermal exposure can be represented as follows:

$$
\begin{aligned}
& {\left[\mathrm{C}_{6} \mathrm{H}_{7} \mathrm{O}_{2}(\mathrm{OH})_{3}\right]_{\mathrm{n}}+\mathrm{xH}_{3} \mathrm{BO}_{3} \longrightarrow} \\
& {\left[\mathrm{C}_{6} \mathrm{H}_{7} \mathrm{O}_{2}\left(\mathrm{OBO}_{2} \mathrm{H}_{2}\right)_{\mathrm{x}}(\mathrm{OH})_{3-\mathrm{x}}\right]_{\mathrm{n}}+\mathrm{xH}_{2} \mathrm{O}}
\end{aligned}
$$

Firmly connected flame retardant composition to the substrate is not washed away during wet treatments, reduced the loss of mass of the sample after exposure to a flame. For the fire resistance test, 5 samples were obtained with different content of components which is presented in Table- 4 .

Properties of the finished material are presented in Table- 5. By analyzing the data, it can be seen that the combined use of acrylic emulsion, boric acid, solution of collagen and potassium persulfate increases the fire resistance textile materials. Along with the change of these key indicators are improving, respectively, and other physical and mechanical performance of materials.

Tests carried out at the boundary values of concentration of the components which leads to the conclusion that a decrease in the concentration of acrylic emulsion is less than $10 \%$, boric acid $>3 \%$ and solution of collagen $>12 \%$ deteriorate the fire resistance performance of textile material. While increasing concentration of acrylic emulsion $<15 \%$, boric acid $<5 \%$ and collagen solution $<18 \%$ flame resistance is not changed, but increases the stiffness of the textile material.

\section{Conclusion}

A composition for flame retardant treatment of textile materials comprising an acrylic emulsion, solution of collagen, boric acid and potassium persulfate is introduced to get a flameretardant textile material. Applying the composition to the material is carried out on the finishing machinery of textile enterprise. The chemical binding of components with cellulosic textile material in the processes of drying and thermal effects provide significant improvement in the flame retardant property.

\section{REFERENCES}

1. A.R. Horrocks and D. Price, Fire Retardant Materials, Woodhead Publishing (2001).
2. J.R. Johnson, Flame Retardant Treatments for Polyester/Cotton Fabrics. Google Patent (1989).

3. W.R. Friberg, Cementuous Fiber Impregnated Construction Composition and Process for Formation Thereof, Google Patent (1989).

4. S. Gottfried, Intumescent Fire-Retardant Composition for High Temperature and Long Duration Protection, Google Patent (1998).

5. G.C. Tesoro and C.H. Meiser Jr., Text. Res. J., 40, 430 (1970); https://doi.org/10.1177/004051757004000506.

6. K. Tang, F. Wang, P. Jia, J. Liu and Q. Wang, J. Am. Leather Chemists Assoc., 102, 52 (2007).

7. J. Zheng, Method of Processing Animal Skin, Google Patent (2012).

8. V.A. Poluboyarav, E.V. Voloskova, V.V. Yankovaya and T.I. Guryanova, Chem. Sustain. Dev., 17, 177 (2009).

9. Z. Zhang, G. Li and B. Shi, J.-Soc. Leather Technol. Chemists, 90, 23 (2006).

10. M. Gómez-Guillén, B. Giménez, M.E. López-Caballero and M.P. Montero, Food Hydrocoll., 25, 1813 (2011); https://doi.org/10.1016/j.foodhyd.2011.02.007.

11. B. Jiang, Y. Zhou, Z. Yang, Z. Wu, G. Huang, L. Lin and X. Zhang, J. Appl. Polym. Sci., 98, 2094 (2005);

https://doi.org/10.1002/app.21992.

12. J. Geesin, L.J. Hendricks, P.A. Falkenstein, J.S. Gordon and R.A. Berg, Arch. Biochem. Biophys., 290, 127 (1991); https://doi.org/10.1016/0003-9861(91)90598-D.

13. T. Shigematsu, S. Tajima, T. Nishikawa, S. Murad, S.R. Pinnell and I. Nishioka, Biochim. Biophys. Acta, 1200, 79 (1994); https://doi.org/10.1016/0304-4165(94)90030-2.

14. L. Wang and Y. Xu, Iran. Polym. J., 15, 467 (2006).

15. S. Lv, R. Gong and Y. Ma, Polym. Adv. Technol., 23, 1343 (2012); https://doi.org/10.1002/pat.2052.

16. M. Zhao, X. Zhou and C.-Z. Zhang, J. Dong Hua Univ., 19, 30 (2002).

17. L. Wang and Y. Xu, Cellulose, 13, 191 (2006); https://doi.org/10.1007/s10570-005-9043-y.

18. E. Nadim, H. Bouhendi, F. Ziaee and A. Nouri, J. Appl. Polym. Sci., 126, 156 (2012); https://doi.org/10.1002/app.36379.

19. N. Karmakar, B. Sastry and R. Singh, Bull. Mater. Sci., 25, 477 (2002); https://doi.org/10.1007/BF02710531.

20. G. Gürdag and S. Sarmad, in eds.: S. Kalia and M.W. Sabaa, Cellulose Graft Copolymers: Synthesis, Properties and Applications, In: Polysaccharide Based Graft Copolymers, Springer, Chap. 2, pp. 15-57 (2013).

21. J.-F. Zhong, X.-S. Chai and S.-Y. Fu, Carbohydr. Polym., 87, 1869 (2012); https://doi.org/10.1016/j.carbpol.2011.07.037.

22. V. Thakur, A. Singha and M. Thakur, Adv. Polym. Technol., 32(S1), E741 (2013); https://doi.org/10.1002/adv.21317.

23. Y. Teramoto and Y. Nishio, Polymer, 44, 2701 (2003); https://doi.org/10.1016/S0032-3861(03)00190-3. 